\title{
Maximum Power Point Tracking Algorithm of Photo Voltaic Power Generation System
}

\author{
SUN Xia \\ School of Electrical and Information \\ Engineering, Anhui University of Science and \\ Technology, \\ Huainan, China, \\ xiasun@aust.edu.cn
}

\author{
WANG Chuanchuan \\ School of Electrical and Information \\ Engineering, Anhui University of Science and \\ Technology, \\ Huainan, China, \\ 13136919@qq.com
}

\begin{abstract}
This paper analyzed methods of Maximum Power Point Tracking Algorithm of Photo voltaic Power Generation System. such as disturbance observation method, the improved disturbance observation method, incremental conductance tracking algorithm, the improved incremental conductance tracking algorithm, these methods were used to improve the efficiency of photo voltaic system, and to increase the utilization rate of solar energy. At last, we put forward outlook of the maximum power point tracking algorithm under complicated illumination conditions. These algorithms can be realized by TMS320VC5402.
\end{abstract}

Keywords: Maximum Power Point Tracking Algorithm; the improved disturbance observation method; the improved incremental conductance tracking algorithm; photo voltaic Power Generation System

\section{Introduction}

Solar energy has the characteristics of clean environmental protection 、 energy saving 、 easy to use and inexhaustible etc. Solar energy has been defined as green and renewable energy and be studied in widespread .But solar radiation has the characteristics of randomness and volatility, the characteristics reduced the output efficiency of the system and influenced working point of solar photo voltaic battery. analyzed methods of Maximum Power Point Tracking Algorithm of photo voltaic Power Generation System can output maximum power ,the methods include disturbance observation method ${ }^{[1] \sim[3]}$ 、 the improved disturbance observation method 、 incremental conductance tracking algorithm、 the improved incremental conductance tracking $\operatorname{algorithm~}^{[4] \sim[6]}$.

\section{Disturbance observation method}

The output of the photo voltaic cell $\mathrm{P}-\mathrm{V}$ curve (figure 1) is a smooth curve, $\mathrm{dP} / \mathrm{dV}>0$ when photo voltaic cells worked at the right side of maximum power point, $\mathrm{dP} / \mathrm{dV}<0$ when photo voltaic cells worked at the left side of maximum power point. Firstly, photo voltaic cells worked at a initial voltage which called V ref. Secondly, add a periodic disturbance by adjust the duty cycle of DC - DC converter. Thirdly, compare the power change,

$\mathrm{dP} / \mathrm{dV}>0$ showed it is a right disturbance, $\mathrm{dP} / \mathrm{dV}<0$ showed it is a wrong disturbance and the direction of disturbance should be turned over, lastly, get the largest photo voltaic battery output power through constant disturbance, disturbance observation flow chart is shown in figure 2.

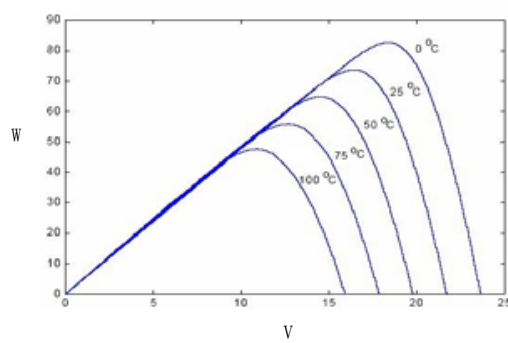

Figure 1. The output of the photo voltaic cell P - V curves 


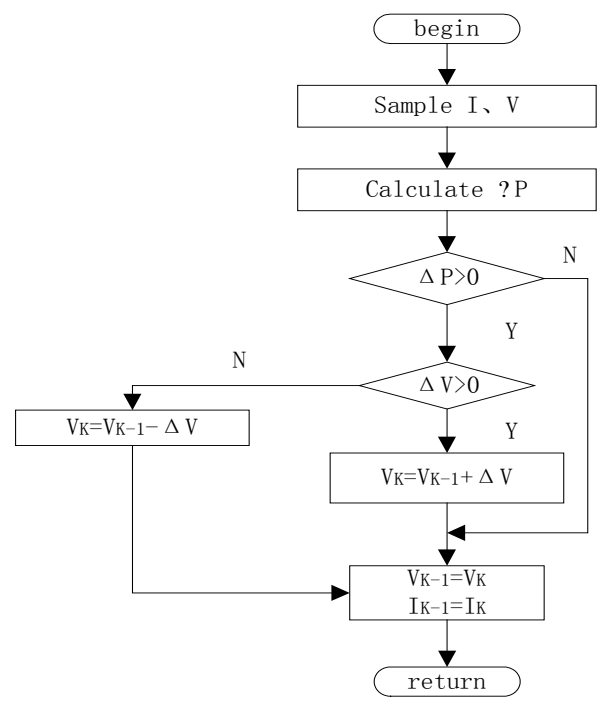

Figure 2. Disturbance observation flow chart

The flow chart showed that disturbance observation method compared the power in time and the power of last time, changed the duty ratio by the situation of working point ${ }^{[7] \sim[8]}$.get the maximum output power if the duty ratio is zero at last.

\section{The improved disturbance observation method}

The numerical of disturbance determines the performance of the algorithm ,the fluctuation range of Maximum Power Point is bigger if numerical of disturbance $\Delta V$ is bigger , and can be coursed bigger energy loss of the system. the corresponding speed of Maximum Power Point is bigger if numerical of disturbance $\Delta V$ is smaller the improved disturbance observation method used $D_{k-1}$ as disturbance of duty cycle to balance this problem. $\Delta D_{k}=M \bullet|\Delta P| / \Delta D_{k-1}, \mathrm{M}$ is the disturbance factor. This method used a longer disturbance step length at first, and adjust the perturbation step size smaller as close to the working point of maximum power point the improved disturbance observation method flow chart shown in figure 3.

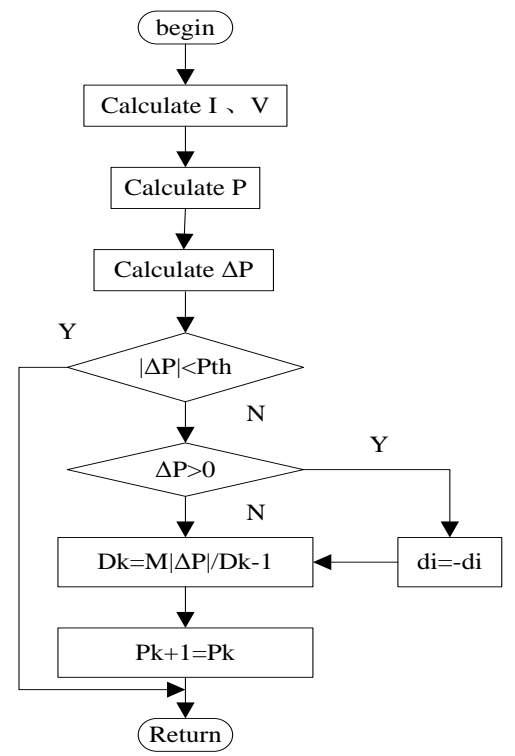

Figure 3. The improved disturbance observation method flow chart

IV. Incremental conductance tracking algorithm

The output of the photo voltaic cell $\mathrm{P}-\mathrm{V}$ curve (figure 1) is a smooth curve, firstly, $\mathrm{dP}=\mathrm{IdU}+\mathrm{UdI}$; secondly, $\mathrm{dP} / \mathrm{dU}=\mathrm{I}+\mathrm{UdI} / \mathrm{dU} ; \quad$ if $\mathrm{dP} / \mathrm{dU}=0, \mathrm{dI} / \mathrm{dU}=-\mathrm{I} / \mathrm{U}$ is the conditions to get maximum power point of photo voltaic array. Incremental conductance tracking algorithm determined direction of reference voltage by compare output conductance's variation and quantity. Incremental conductance tracking algorithm flow chart shown in figure 4.

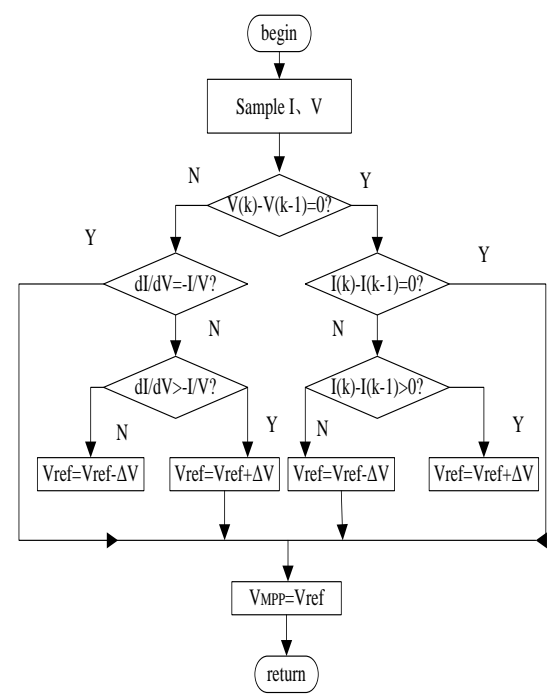

Figure 4. Incremental conductance tracking algorithm flow chart shown 
V. The improved incremental conductance tracking algorithm

incremental conductance tracking algorithm used a constant as step length, it can caused severe oscillation if the step length is bigger and it can caused low dynamic characteristics if the step length is smaller ${ }^{[9] \sim[10]}$.the improved incremental conductance tracking algorithm select a reference value and then used incremental conductance tracking algorithm to close Maximum Power Point by variant step length ${ }^{[11 \sim[12]}$.the improved incremental conductance tracking algorithm flow chart shown in figure 5.

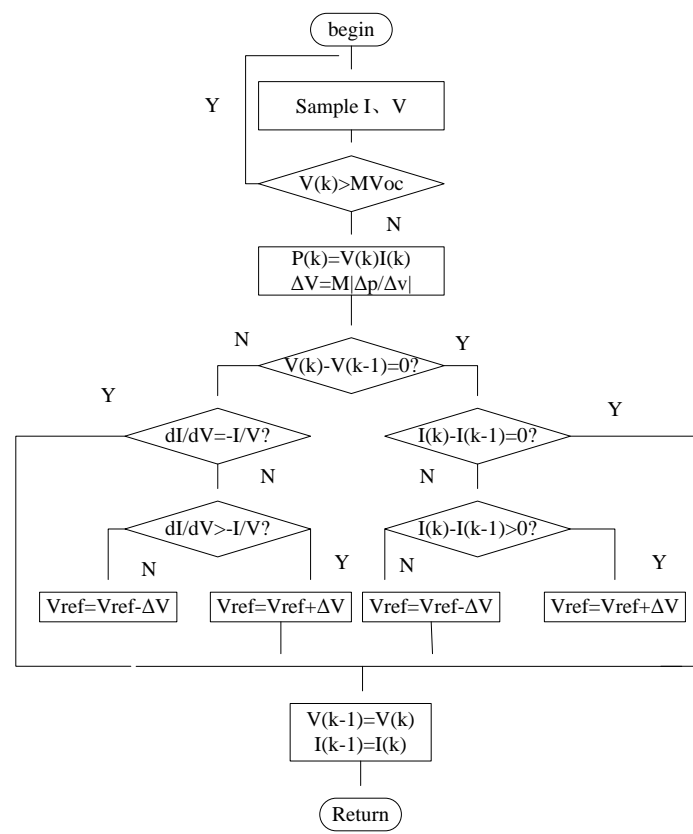

Figure 5. Improved incremental conductance tracking algorithm flow chart

VI. Hardware design

TMS320VC5402 is used as control core, it has two voltages, the core voltage is $1.8 \mathrm{~V}$, the IO voltage is $3.3 \mathrm{~V}$, and the reset circuit 、 data memory expansion 、 program memory expansion are shown in figure 6-9. MAX705/706 is an automatic reset circuit with functions of monitoring the CMOS. Data memory ICSI64LV16 and program memory AT29LV1024 circuit respectively has 16 address and data lines. hardware include analog signals frication and amplification, ADC, LCD, voice alarm, printer, data storage unit, program storage unit.

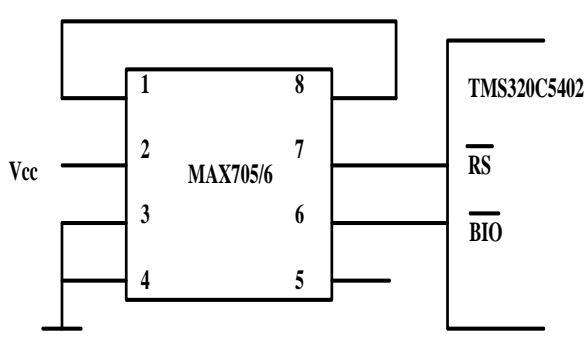

Figure6. Reset circuit

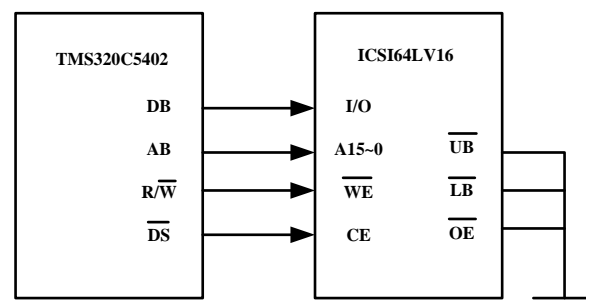

Figure7. Date memory expansion

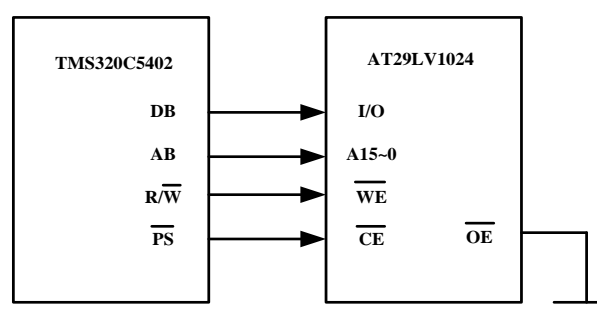

Figure8. Program memory expansion

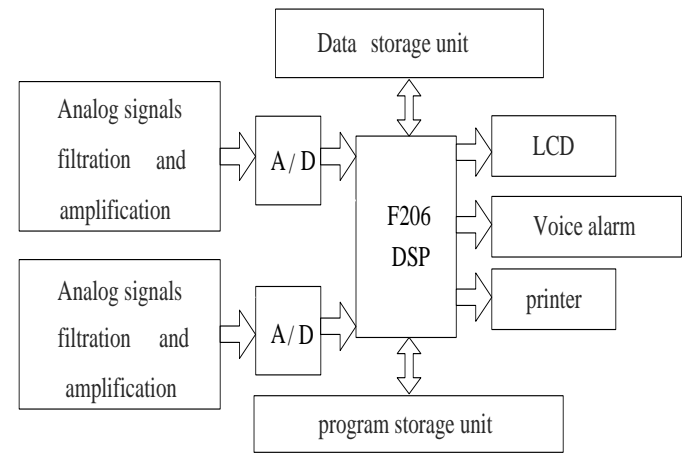

Figure 9. The Block Diagram of Hardware

To sum up ,disturbance observation method, the improved disturbance observation method, incremental conductance tracking algorithm, the improved incremental conductance tracking algorithm, these methods have advantages and disadvantages ,Considering the complex lighting condition of maximum power point tracking, can used a variety of methods for tracking regulation and stability control, such as particle swarm optimization algorithm, fuzzy algorithm, Neural 
network algorithm, Load tracking control algorithm, Light source tracking control algorithm, Open circuit voltage method etc.

solar energy as one of the main clean energy plays a very important role at strong power of new energy development in today, in order to obtain a stable, efficient energy, the increasingly mature control algorithm of maximum power point of solar battery track laid a solid foundation, with the continuous development of power electronic technology, solar energy maximum power point tracking control of intelligent controller, integration will inevitably become the research emphasis in the future.

\section{ACKNOWLEDGMENT}

This work is supported by the 5th backbone of middle-aged and young teachers of Anhui University of Science and Technology (No.201529), College students' innovation and entrepreneurship Project of Anhui Province (No.201510361054), Science and technology plan project of Huainan city (No.2014A1801). RC-16 Domestic Visting Project of Anhui Province (No.gxfxZD2016071).

\section{REFERENCES}

[1]ZHANG Y F, WEI CH, Lin SH B. A maximum power point tracking method based on tabu search for PV system under partially shaded conditions[C].IET conference on renewable power generation, 2011,Edinburgh, U.K, 2011: 52-56.

[2]CHIN C S, TAN M K, NEELAKANTAN.P, et .Optimization of partially shaded PV array using fuzzy MPPT[C]. IEEE colloquium on humanities, science and engineering, 2011, Penang,Malaysia, 2011: 481-486.

[3] Yu Xiaopeng,A Method of Invert-er Modeling in Photovoltatic System Based on Finite State Machine[J].Electric Power Science and Engineering.2015,31(6):18-22

[4]CAI Ming xiang 1, JIANG Xi $\square$ meng2 , XIE Wei1,Improved Increment Conductance MPPT Method for Photo voltaic System [J]., ELECTRIC DRIVE 2011,V41(7)P:21-24

[5]Zhao jinli,Yu yingying.etc.A fast determination method of
DG capacity in distribution network based on conic programming[J].Transactions of China Electrotechnical society,2014,29(12):173-179

[6]Bai Muke,Tang Wei,etc.Multi-objective coordinated planning of distribution network incorporating distributed generation based on chance constrained programming $[\mathrm{J}]$.Transactions of China electrotechnical societh,2013,28(10):346-354

[7]Parlak, K.S.; Can, H., " A new MPPT method for PV array system under partially shaded conditions," Power Electronics for Distributed Generation Systems (PEDG), 2012 3rd IEEE International Symposium on , vol., no., pp.437,441, 25-28 June 2012.

[8]Coelho, R.F.; Concer, F.M.; Martins, D.C., " A simplified analysis of DC-DC converters applied as maximum power point tracker in photovoltaic systems," Power Electronics for Distributed Generation Systems (PEDG), 2010 2nd IEEE International Symposium on , vol., no., pp.29,34, 16-18 June 2010.

[9]B. N. Alajmi, K. H. Ahmed, S. J. Finney and B. W. Williams "A Maximum Power Point Tracking Technique for Partially Shaded Photovoltaic Systems in Microgrids", IEEE Transactions on Industrial Electronics, vol. 60, pp.1596-1606 2013

[10]Z. Salam, K. Ishaque and H. Taheri "An improved two-diode photovoltaic (PV) model for PV system", 2010 Joint International Conference on Power Electronics, Drives and Energy Systems \& 2010 Power India, pp.1 -5

[11]M. Herman, M. Jankovec and M. Topic "Optimal I-V Curve Scan Time of Solar Cells and Modules in Light of Irradiance Level", International Journal of Photoenergy, vol. 2012, pp.1-11 2012

[12]E. Koutroulis and F. Blaabjerg "A New Technique for Tracking the Global Maximum Power Point of PV Arrays Operating Under Partial-Shading Conditions", IEEE Journal of Photovoltaics, vol. 2, pp.184-190 2012 